\title{
Large Scale Analysis of Complex Permittivity of Breast Cancer in Microwave Band
}

\author{
Yoshihiko Kuwahara1 ${ }^{*}$, Akira Nozaki', Kimihito Fujii ${ }^{2}$ \\ ${ }^{1}$ Department of Electric and Electronical Engineering, Faculty of Engineering, Shizuoka University, Hamamatsu, Japan \\ ${ }^{2}$ Division of Breast and Endocrine Surgery, Department of Surgery, Aichi Medical University, Nagakute, Japan \\ Email: *kuwahara.yoshihiko@shizuoka.ac.jp
}

How to cite this paper: Kuwahara, Y., Nozaki, A. and Fujii, K. (2020) Large Scale Analysis of Complex Permittivity of Breast Cancer in Microwave Band. Advances in Breast Cancer Research, 9, 101-109. https://doi.org/10.4236/abcr.2020.94008

Received: August 15, 2020

Accepted: September 12, 2020

Published: September 15, 2020

Copyright (c) 2020 by author(s) and Scientific Research Publishing Inc. This work is licensed under the Creative Commons Attribution International License (CC BY 4.0).

http://creativecommons.org/licenses/by/4.0/

(c) (i) Open Access

\begin{abstract}
To obtain some prior knowledge of breast cancer detection by microwave imaging, we have measured and analyzed the complex permittivity of tissues extracted from over 140 breast cancer surgeries. The relative permittivity and conductivity of tumor at $1.6 \mathrm{GHz}$ were $17.5 \%$ and $16.2 \%$ higher than those of mammary gland tissue, respectively. In invasive ductal carcinoma of scirrhous type, 8 out of 64 had higher relative permittivity and conductivity of mammary gland than those of tumor. However, when evaluated by the Debye parameter considering the frequency dependence of the tissue, it is rare that $\varepsilon_{\infty}$ and $\Delta \varepsilon$ of cancer are simultaneously lower than those of mammary gland. The relative permittivity and conductivity of fibroadenoma are almost the same as those of mammary glands. The relative permittivity and conductivity of each tissue showed strong linearity. Microwave imaging requires accurate reconstruction of $\mathcal{E}_{\infty}$ and $\Delta \varepsilon$ to distinguish cancer from normal tissue.
\end{abstract}

\section{Keywords}

Breast Cancer Detection, Microwave Imaging, Complex Permittivity, Debye Model

\section{Introduction}

Research on breast cancer detection by microwave imaging has attracted extensive attention [1] [2] [3]. The principle of microwave imaging is the detection of scattered waves generated by the difference in the complex permittivity of tissues in the microwave band [4]. In general, cancer tissues are rich in blood vessels and are reported to have a higher relative permittivity and conductivity than other tissues. In [5] and [6], categorization was achieved according to the density of the mammary gland, and the measurement results of the complex permittivity 
of the breast tissue were presented. Ref. [7] shows that the relative permittivity and conductivity of tumors specimen depend on the volume ratio of tumor cells contained. However, these studies do not mention the pathological findings of cancerous tumors. To investigate the pathological type of cancerous tumors considering individual differences, we have measured the complex permittivity of the breast tissue extracted by breast cancer surgery [8]. In this paper, we present our measurement and analysis results.

\section{Measurement}

\subsection{Method}

The electrical constants of breast tissue can be measured using a dielectric probe [9] [10]. Ref. [9] shows that a cylindrical region with a depth of $1.5 \mathrm{~mm}$ and a radius of $3.75 \mathrm{~mm}$ is required to achieve a measurement error of $10 \%$ using a 2.2 $\mathrm{mm}$ diameter dielectric probe. In our study, we measure the complex permittivity of breast tissue using a $2.2 \mathrm{~mm}$ diameter dielectric probe in the dielectric measurement kit Keysight $85070 \mathrm{E}$ and a vector network analyzer, E5071C. The measurement range is $1-8 \mathrm{GHz}$.

In recent year, since breast cancer is often detected at an early stage, the size of the tumors removed by surgery has become smaller. To investigate the minimum required volume of a specimen, the dielectric constant was measured by placing ketchup in containers of various volumes.

The container, apart from the Petri dish, was created using a 3D printer. The material of the container is ABS resin. Figure 1 illustrates the appearance of the container and measurement system.

In the preliminary measurement using ketchup, for a container measuring 0.5 $\times 0.5 \times 0.5 \mathrm{~cm}$, an error of $3 \%$ occurred with respect to the measurement result of the Petri dish. However, in a container measuring $1 \times 1 \times 0.5 \mathrm{~cm}$, the error reduces to $1 \%$ or lower. We selected the $1 \times 1 \times 0.5 \mathrm{~cm}$ container for analysis. Samples removed by surgery were cut into fats, mammary glands, and cancerous tumor tissues. Each tissue was placed in a container and the probe was pressed downwards to measure the complex permittivity. Figure 2 shows a photograph of the tissue put in a container.

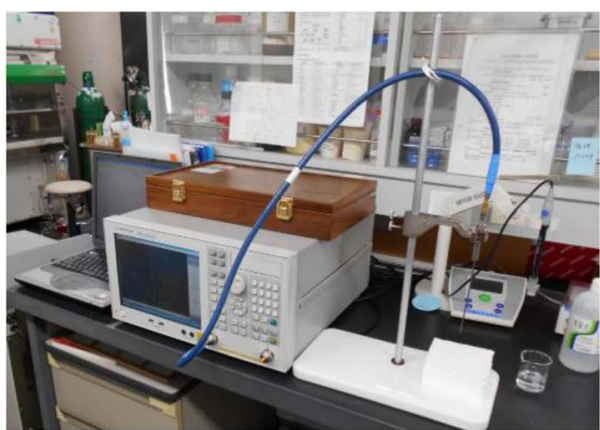

Equipment

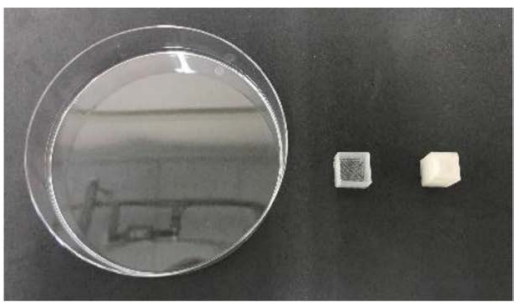

Petri dish, $1 \times 1 \times 0.5 \mathrm{~cm}$, $5 \times 0.5 \times 0.5 \mathrm{~cm}$ container

Figure 1. Measurement system. 


\subsection{Tissue Sample Collection}

During the breast cancer surgery performed at Aichi Medical University from May 2018 to July 2020, breast tissue specimens were collected from 140 patients who consented to the specimen collection. Table 1 exhibits the outline of the samples. Here, mammary gland tissues of the highest possible density were collected from every patient.

Figure 3 summarizes the cancer stage, and mammary gland findings by X-ray mammography, and patient's age. In recent years, there have been many stage 0 and stage 1 (tumors less than $2 \mathrm{~cm}$ ) surgery as shown in Figure 3(a), and it has not been possible to collect tumor tissues that can withstand measurement from all patients. X-ray mammography findings of mammary gland density in Figure 3(b) revealed that nearly half of the patients had dense mammary glands. Due to the disappearance of mammary gland tissue at an older age, it was not possible to obtain mammary gland tissue that could be used for measurement from all patients. The number of samples for each pathology is shown in Table 1. Invasive ductal carcinoma accounts for $84 \%$, of which more than half are scirrhous type. Fibroadenoma is more common in young women, with a minimum age of onset of 15 in this study. Five patients in their $30 \mathrm{~s}$ with invasive ductal carcinoma

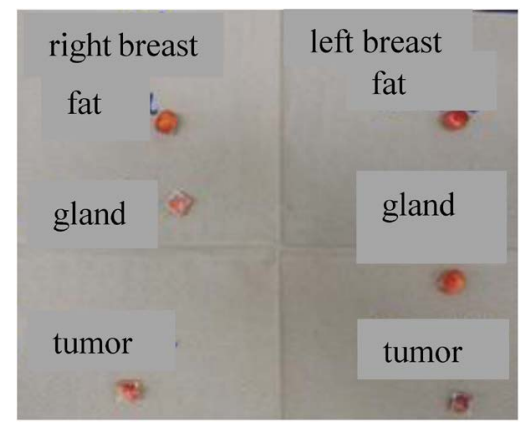

Figure 2. Tissue samples.

Table 1. Number of sample.

\begin{tabular}{ccccccc}
\hline \multicolumn{2}{c}{ histological classification } & patient & tumor & gland & fat & age \\
\hline $\begin{array}{c}\text { invasive ductal } \\
\text { carcinoma }\end{array}$ & tuble forming & 7 & 6 & 6 & 6 & 59.6 \\
& solid & 38 & 35 & 23 & 36 & 63.3 \\
& $\begin{array}{c}\text { scirrhous } \\
\text { others }\end{array}$ & 64 & 52 & 46 & 58 & 61 \\
special & 9 & 8 & 6 & 9 & 59.9 \\
& $\begin{array}{c}\text { invasive lobular } \\
\text { carcinoma }\end{array}$ & 4 & 4 & 4 & 4 & 63.6 \\
& $\begin{array}{c}\text { mucinous carcinoma } \\
\text { others }\end{array}$ & 6 & 6 & 4 & 5 & 66.8 \\
mixed connective tissue & fibroadenoma & 5 & 0 & 5 & 5 & 49.4 \\
and epithelial tumors & phyllodes tumor & 2 & 2 & 0 & 1 & 54.2 \\
\multicolumn{1}{c}{ total } & & 140 & 118 & 98 & 126 & 60.3 \\
\hline
\end{tabular}




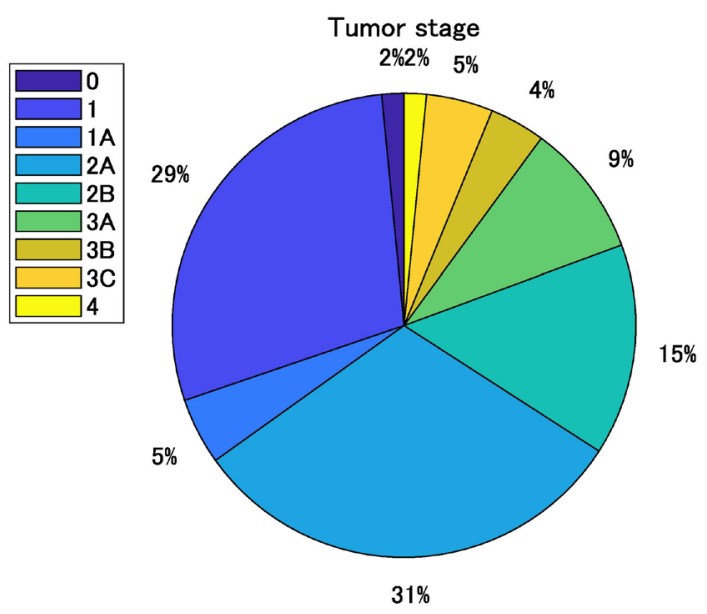

(a)
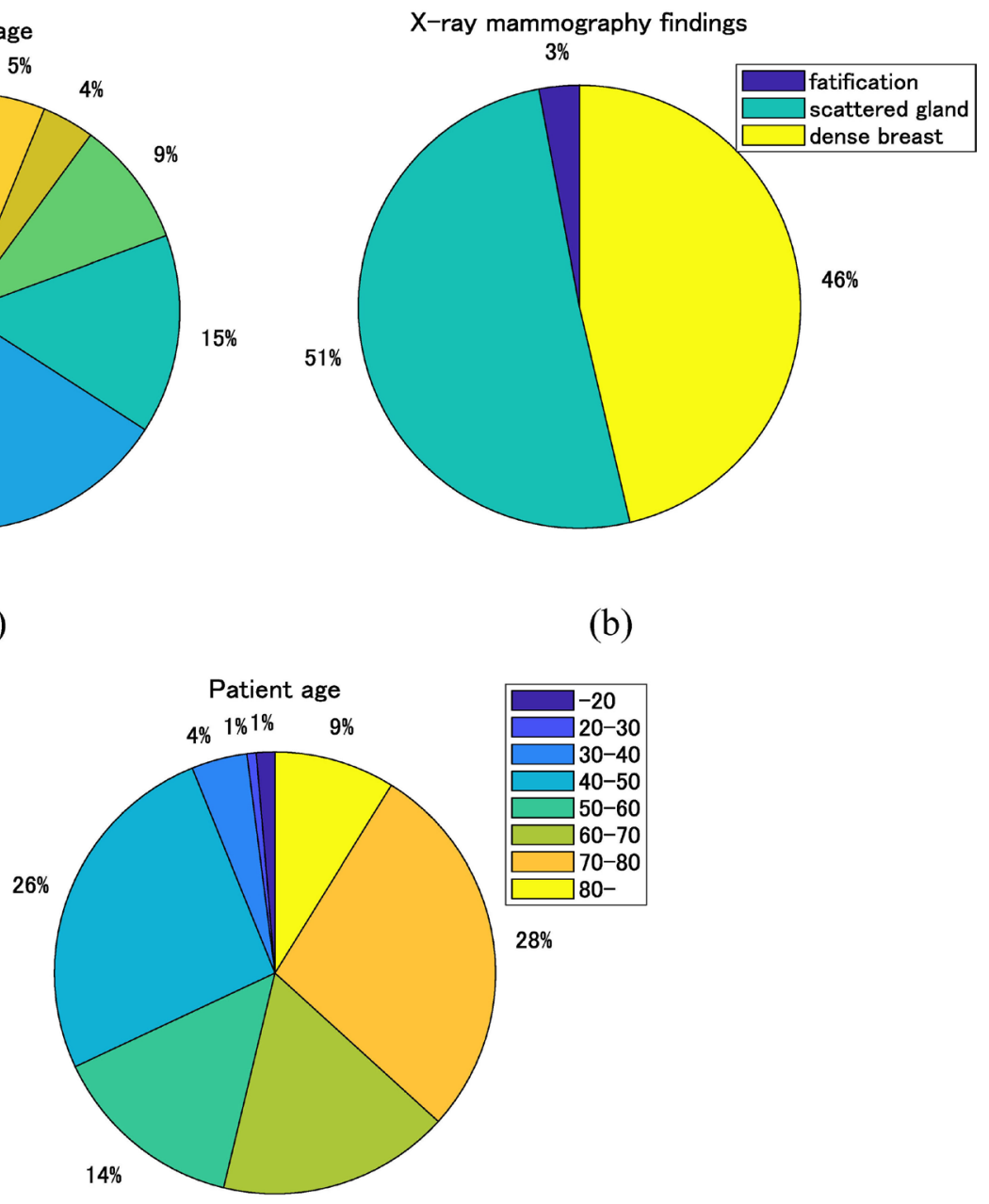

$17 \%$

(c)

Figure 3. Tissue samples. (a) Tumor stage; (b) Mammary gland density; (c) Patient age.

account for 4\% (See Figure 3(c)) of all patients with invasive ductal carcinoma. All of the patients were at stage 2. Women in their $30 \mathrm{~s}$ are not eligible for breast cancer screening in Japan. When cancer grows, it is said that necrosis and calcification occur in the center of the cancer. X-ray mammography detects this calcification. Pathological findings showed necrosis in 6 cases and calcification in 11 cases.

\section{Results}

\subsection{Complex Permittivity}

Figure 4 shows a typical example of the complex relative permittivity of the sample measured using the measurement system shown in Figure 1. The measurement result that we expect is that the relative permittivity of tumor tissue is considerably higher than that of mammary tissue, as shown in Figure 4(a). However, as shown in Figure 4(b), there were 8 cases in which the relative permittivity of the mammary gland tissue was higher than that of the tumor tissue 
in the scirrhous type and 1 case in the solid type. The reason for the opposite properties may be that, as noted in the Ref. [7], not all areas of the tumor sample are filled with tumor tissue.

Table 2 shows the average of relative permittivity $\varepsilon_{r}$ and conductivity $\sigma$ of tumor and mammary gland at $1.6 \mathrm{GHz}$ by pathology. On average, the relative permittivity of cancer is $17.5 \%$ higher than that of mammary gland tissue, and the conductivity is $16.2 \%$ higher. Fibroadenoma has the lowest contrast between the relative permittivity and conductivity of cancer and mammary gland. Fibroadenoma is common in women in their teens and $20 \mathrm{~s}$, has well-defined lump boundaries, and is often classified as a benign tumor. The disease is not a tumor, but is made up of an excessive amount of normal cells (anaplasia), so there is almost no difference in contrast with the mammary gland. Among the invasive cancers, tumors that are said to be a special type have a large contrast

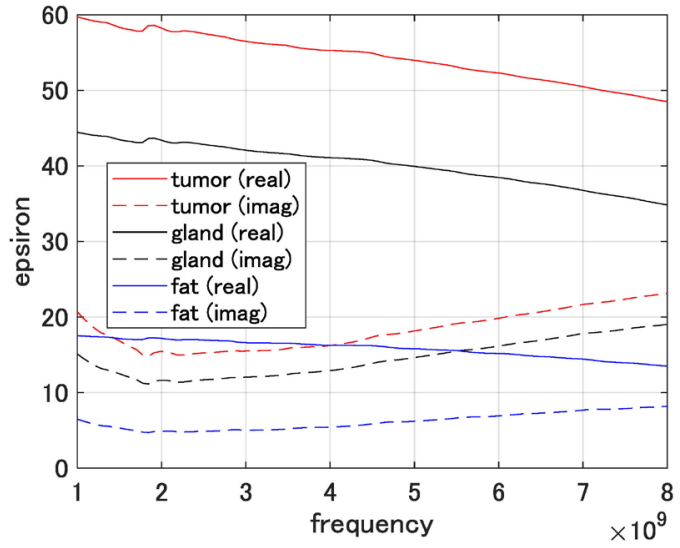

(a)

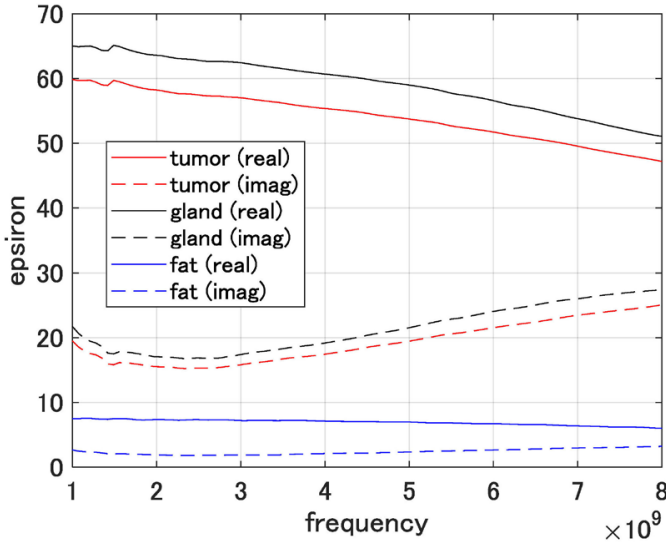

(b)

Figure 4. Measurement examples of the complex permittivity. (a) Solid tubular carcinoma (Age 49, dense breast); (b) Scirrhous carcinoma (Age 41, dense breast).

Table 2. Permittivity and conductivity $(1.6 \mathrm{GHz})$.

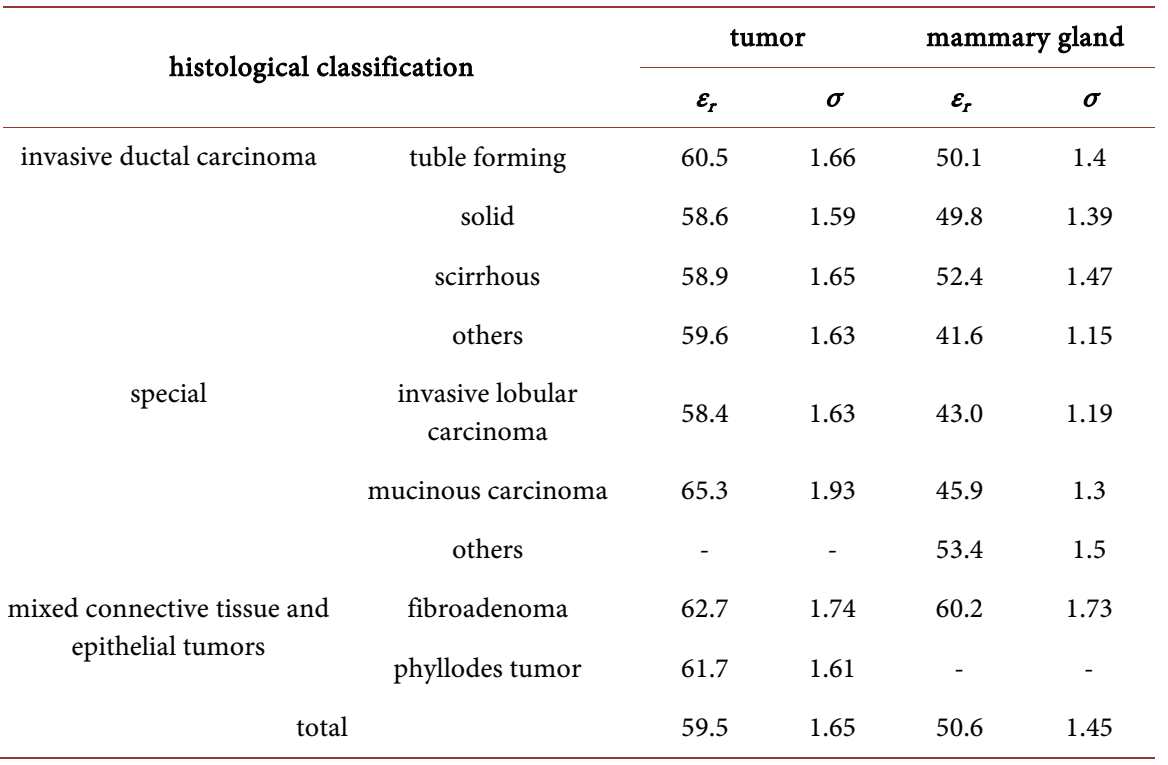


between the mammary gland and the cancer, and good detection by microwave imaging can be expected. The scirrhous type is the most common type of invasive ductal carcinoma, but the contrast between the relative permittivity and the conductivity of the cancer and mammary gland tissue is $12 \%$, which is relatively small. Therefore, MI requires the ability to identify objects with a contrast of about $10 \%$.

\subsection{Debye Parameter}

The complex permittivity of the frequency dependent medium can be represented by the Debye model, as stated by Equation (1), using $\omega$ as an angular frequency and $\varepsilon_{0}$ as a vacuum permittivity

$$
\frac{\varepsilon(\omega)}{\varepsilon_{0}}=\varepsilon_{\infty}+\frac{\sigma_{s}}{j \omega \varepsilon_{0}}+\frac{\Delta \varepsilon}{1+j \omega \tau}
$$

In the Debye model, the frequency characteristics can be approximated by four parameters, namely, $\mathcal{E}_{\infty}, \Delta \mathcal{E}$, $\sigma_{s}$, and $\tau$. The four parameters have been estimated from the measurement results of the complex permittivity using the Simplex method [11].

Table 3 shows the average Debye parameters for tumor and mammary gland by pathology. The Debye parameter is a parameter considering dispersibility (frequency characteristic).

Relaxation time $\tau$ does not differ significantly between tumor tissue and mammary gland tissue. This is an important prior knowledge of tomography for solving the inverse scattering problem [12]. Among the Debye parameters, $\mathcal{E}_{\infty}$ has an extremely high contrast between cancer and mammary gland. By utilizing this feature, it becomes easy to distinguish between the mammary gland and cancer in microwave imaging.

Table 3. Debye parameters.

\begin{tabular}{|c|c|c|c|c|c|c|c|c|c|}
\hline \multicolumn{2}{|c|}{ histological classification } & \multicolumn{4}{|c|}{ tumor } & \multicolumn{4}{|c|}{ mammary gland } \\
\hline \multirow{3}{*}{$\begin{array}{l}\text { invasive ductal } \\
\text { carcinoma }\end{array}$} & & $\varepsilon_{\infty}$ & $\Delta \varepsilon$ & $\sigma_{\mathrm{s}}$ & $\tau$ & $\varepsilon_{\infty}$ & $\Delta \varepsilon$ & $\sigma_{\mathrm{s}}$ & $\tau$ \\
\hline & tuble forming & 5.63 & 55.9 & 0.94 & 11.6 & 1.25 & 49.7 & 0.77 & 11.5 \\
\hline & solid & 3.91 & 55.5 & 0.90 & 11.2 & 1.56 & 49.0 & 0.81 & 10.7 \\
\hline \multirow{4}{*}{ special } & scirrhous & 4.59 & 55.2 & 0.95 & 11.4 & 0.59 & 52.5 & 0.85 & 10.5 \\
\hline & others & 3.39 & 57.0 & 0.97 & 10.3 & 1.81 & 40.4 & 0.64 & 10.3 \\
\hline & $\begin{array}{c}\text { invasive lobular } \\
\text { carcinoma }\end{array}$ & 5.28 & 53.9 & 0.97 & 11.0 & -0.45 & 44.0 & 0.70 & 9.9 \\
\hline & $\begin{array}{l}\text { mucinous } \\
\text { carcinoma }\end{array}$ & -1.76 & 66.2 & 0.98 & 10.3 & -4.71 & 47.0 & 0.68 & 9.8 \\
\hline \multirow{3}{*}{$\begin{array}{l}\text { mixed connective } \\
\text { tissue and epithelial } \\
\text { tumors }\end{array}$} & others & - & - & - & - & -1.88 & 55.9 & 0.90 & 9.7 \\
\hline & fibroadenoma & 1.46 & 61.8 & 0.96 & 11.1 & 1.99 & 56.3 & 0.96 & 11.8 \\
\hline & phyllodes tumor & -0.45 & 63.0 & 0.89 & 10.3 & - & - & - & - \\
\hline \multicolumn{2}{|c|}{ total } & 3.87 & 56.3 & 0.94 & 11.2 & 0.64 & 50.5 & 0.81 & 10.6 \\
\hline
\end{tabular}


Figure 5 shows a plot of Debye parameters and age for tumor and mammary gland. $\Delta \varepsilon$ and $\sigma$ decrease with age. Unlike other tumors, fibroadenoma has small $\varepsilon_{\infty}$ and large $\Delta \varepsilon$.

Figure 6 shows the distribution of differences between tumor and mammary gland by extracting two parameters from Debye parameters. Points on the negative side of the Cartesian axes indicate when the tumor parameter is less than the mammary parameter. In the plot of $\mathcal{E}_{\infty}$ and $\Delta \mathcal{E}$, there are only four cases where the tumor parameter is smaller than the mammary gland. If microwave imaging can accurately estimate these parameters, it will be possible to accurately distinguish between mammary gland and tumor tissue.

\subsection{Linear Relationship between Relative Permittivity and Conductivity}

Figure $7(\mathrm{a})$ is a plot showing the relationship between relative permittivity $\mathcal{E}_{\mathrm{r}}$ and conductivity $\sigma$ of breast tissue at $1.6 \mathrm{GHz}$, and Figure 7(b) is a plot showing the relationship between $\Delta \varepsilon$ and $\sigma$. They show that there is a strong correlation between $\mathcal{E}_{\mathrm{r}}$ and $\sigma$, or $\Delta \varepsilon$ and $\sigma$ regardless of the organ. This is important priori
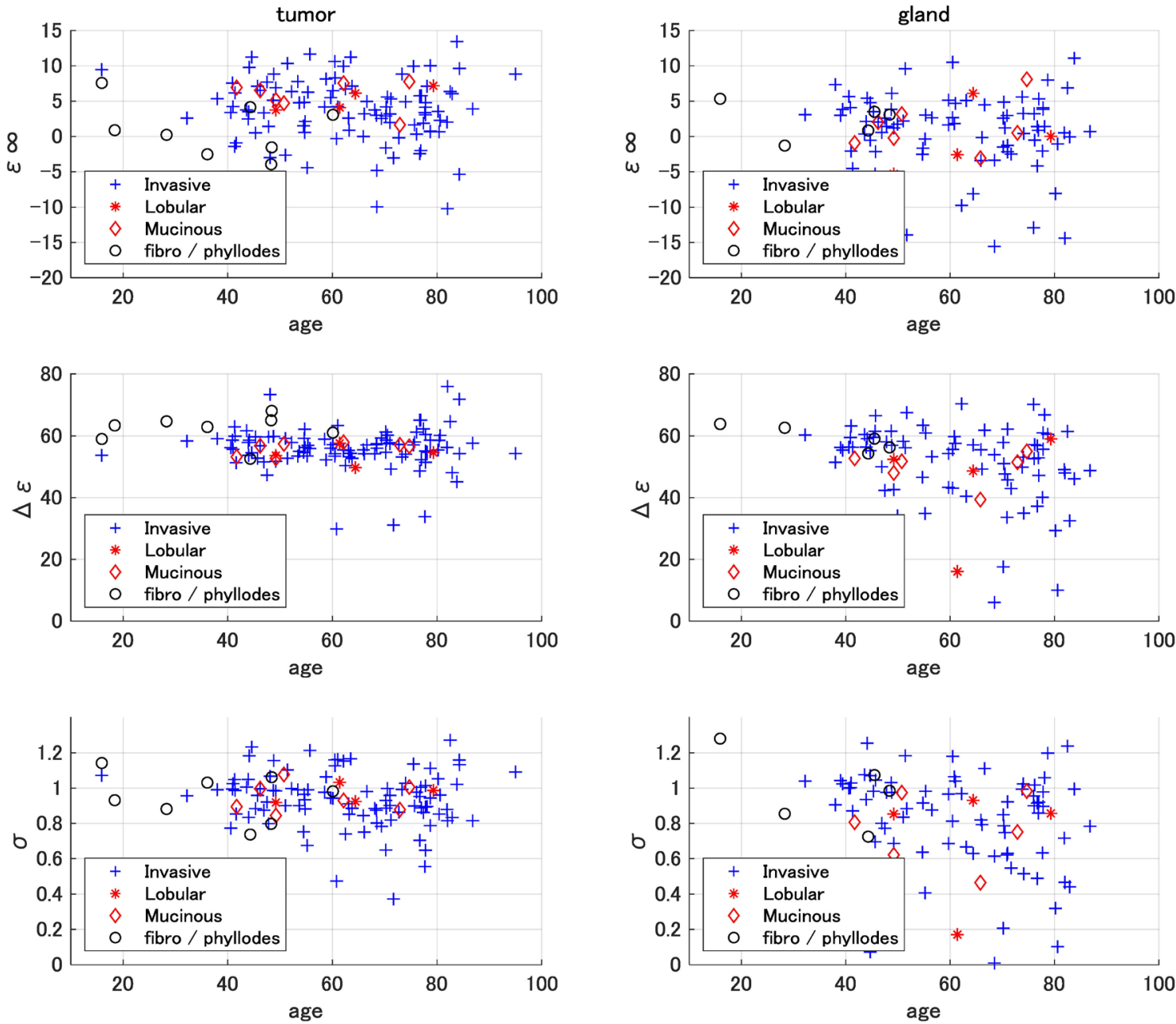

Figure 5. Debye parameter.vs. age. 


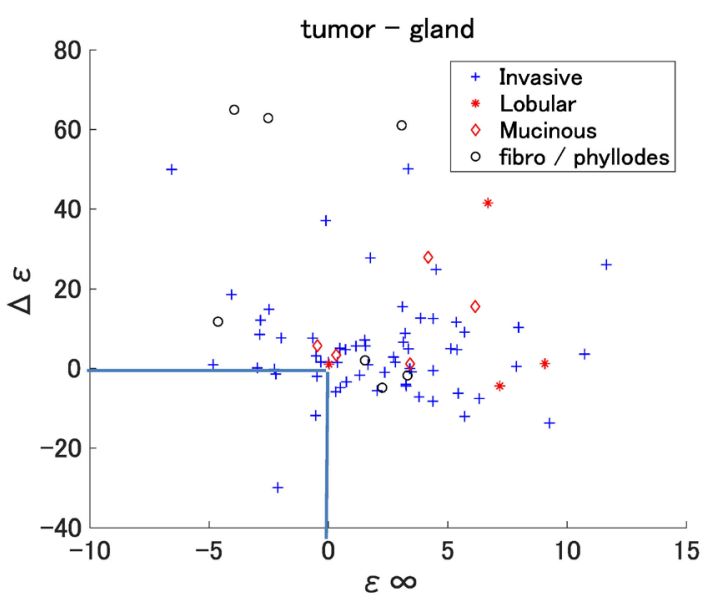

(a)

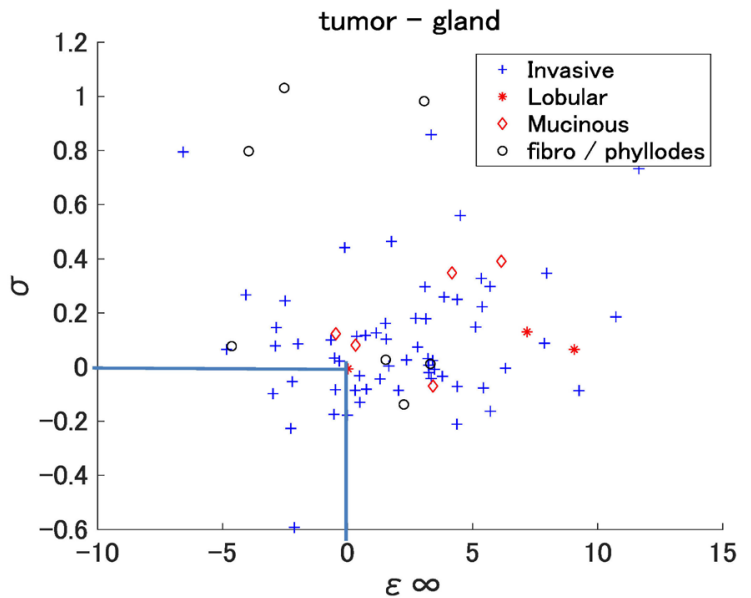

(b)

Figure 6. Contrast of Debye parameter between tumor and mammary gland. (a) $\varepsilon_{\infty}$ vs. $\Delta \varepsilon$; (b) $\varepsilon_{\infty}$ vs. $\sigma_{s}$.

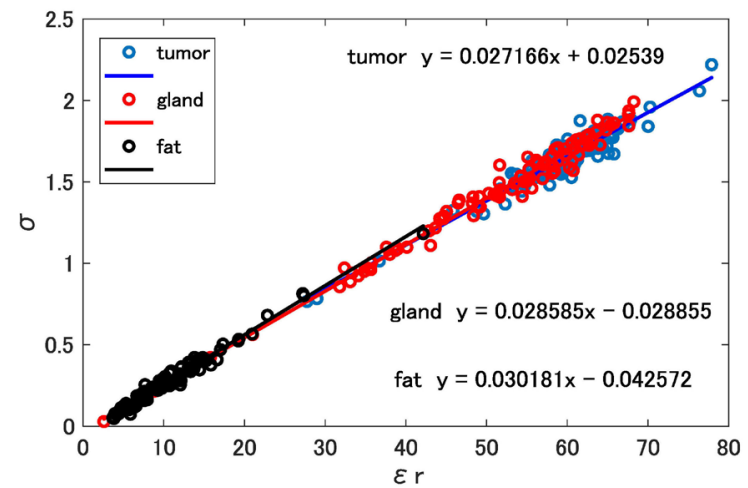

(a)

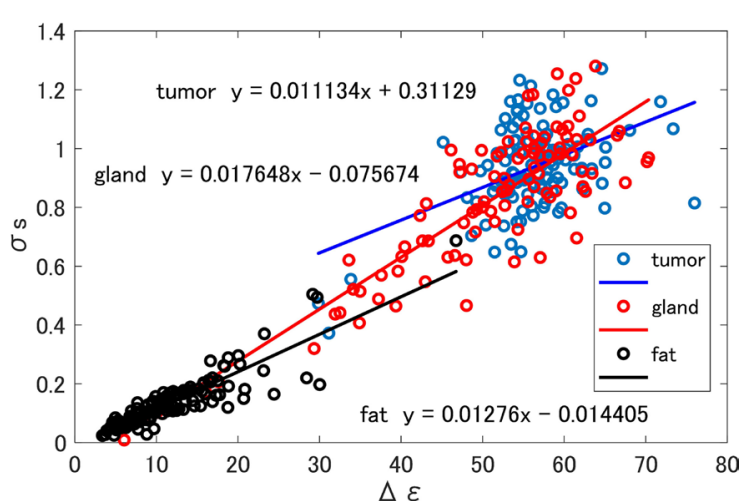

(b)

Figure 7. Linear relationship between relative permittivity and conductivity. (a) $\mathcal{E}_{\mathrm{r}}$ vs. $\sigma$; (b) $\Delta \varepsilon$ vs. $\sigma_{\mathrm{s}}$.

information for tomography to solve the inverse scattering problem.

\section{Conclusion}

The complex permittivity of the tissue samples extracted from the surgery of 140 cases of breast cancer was measured and analyzed. The average contrast of the complex permittivity of fibroadenoma and mammary tissue is small. The mean contrast of the complex permittivity of the scirrhous type of invasive ductal carcinoma and the mammary gland tissue is $12 \%$, which is not so large. In $17 \%$ of scirrhous type, the complex permittivity of mammary gland tissue exceeds those of cancerous tissue. In such a case, reconstruction of Debye parameters is effective. It requires accurate reconstruction of the Debye parameter $\mathcal{E}_{\infty}$ rather than the conductivity and relative permittivity for microwave imaging to distinguish cancerous tumor from normal tissue.

\section{Conflicts of Interest}

The authors declare no conflicts of interest regarding the publication of this paper. 


\section{References}

[1] Nikolova, N.K. (2011) Microwave Imaging for Breast Cancer. IEEE Microwave Magazine, 12, 78-94. https://doi.org/10.1109/MMM.2011.942702

[2] Kuwahara, Y. (2017) Microwave Imaging for Early Breast Cancer Detection. In: Malik, A.M., Ed., New Perspectives in Breast Imaging, Intech, Rijeka, Croatia, 45-71. https://doi.org/10.5772/intechopen.69562

[3] Song, H., Sasada, S., et al. (2017) Detectability of Breast Tumor by a Hand-Held Impulse-Radar Detector: Performance Evaluation and Pilot Clinical Study. Scientific Reports, 7, Article No. 16353. https://doi.org/10.1038/s41598-017-16617-6

[4] Paulsen, K.D., Meaney, P.M. and Gilman, L.C. (2005) Alternative Breast Imaging. Springer, Berlin. https://doi.org/10.1007/b101336

[5] Lazebnik, M., McCartney, L., et al. (2007) A Large-Scale Study of the Ultra-Wideband Microwave Dielectric Properties of Normal Breast Tissue Obtained from Reduction Surgeries. Physics in Medicine \& Biology, 52, 2637-2659. https://doi.org/10.1088/0031-9155/52/10/001

[6] Lazebnik, M., McCartney, L., et al. (2007) A Large Scale Study of the Ultra-Wideband Microwave Dielectric Properties of Normal, Benign, and Malignant Breast Tissues Obtained from Cancer Surgeries. Physics in Medicine \& Biology, 52, 6093-6115. https://doi.org/10.1088/0031-9155/52/20/002

[7] Sugitani, T., Kubota, S., et al. (2014) Complex Permittivities of Breast Tumor Tisues Obtained from Cancer Surgeries. Applied Physics Letters, 104, Article ID: 253702. https://doi.org/10.1063/1.4885087

[8] Kuwahara, Y., Nakada, A., et al. (2019) Measurement and Analysis of Complex Permittivity of Breast Cancer in Microwave Band. 201941 st Annual International Conference of the IEEE Engineering in Medicine and Biology Society (EMBC), Berlin, 23-27 July 2019, 2929-2932. https://doi.org/10.1109/EMBC.2019.8857791

[9] Hagl, D.M., Popovic, D., et al. (2003) Sensing Volume of Open-Ended Coaxial Probes for Dielectric Characterization of Breast Tissue at Microwave Frequencies. IEEE Transactions on Microwave Theory and Techniques, 51, 1194-1206. https://doi.org/10.1109/TMTT.2003.809626

[10] Popovic, D., McCartney, L., et al. (2005) Precision Open-Ended Coaxial Probes for in Vivo and ex Vivo Dielectric Spectroscopy of Biological Tissues at Microwave Frequencies. IEEE Transactions on Microwave Theory and Techniques, 53, 1713-1722. https://doi.org/10.1109/TMTT.2005.847111

[11] Press, W.H., Teukolski, S.A., et al. (2007) Numerical Recipes in C. Cambridge University Press, Cambridge.

[12] Shea, J.D., Kosmas, P., Hagness, S.C. and Van Veen, B.D. (2010). Three Dimensional Microwave Imaging of Realistic Numerical Breast Phantoms via a Multiple Frequency Inverse Scattering Technique. Medical Physics, 37, 4210-4226. https://doi.org/10.1118/1.3443569 